\title{
LOS EFECTOS DE LA ADVERSIDAD CLIMÁTICA Y SANITARIA SOBRE LA AGRICULTURA Y LA SOCIEDAD CASTELLONENSE DEL SIGLO XVIII
}

\author{
CRISTIAN PARDO NACHER \\ Universidad de Valencia \\ cpardonacher@gmail.com
}

\section{Resumen}

El presente artículo recurre a la microhistoria para analizar los archivos municipales de la Plana de Castelló, con el objetivo de obtener nuevas referencias sobre la evolución climática de la fachada mediterránea peninsular durante un periodo cronológico concreto: el siglo XVIII, enclavado en los estadios finales de la Pequeña Edad de Hielo. Con esta finalidad, se abordarán las principales sequías, precipitaciones extremas, plagas y epidemias acontecidas en la Plana de Castelló durante el Setecientos, y aquellos recursos, tanto religiosos como seculares, utilizados para prevenir, primero, y erradicar, después, las adversidades climáticas, biológicas y sanitarias.

Palabras clave: Inundaciones; Sequías; Plagas; Pedrizos; Epidemias; Plana de Castelló.

\begin{abstract}
Climate and health adversity in Castelló during $18^{\text {th }}$ century

This paper discusses a micro historical study of the climate in lands along the Mediterranean coast of Spain at a specific time in history, namely the 18th century, towards the end of the Little Ice Age. Data obtained from the municipal archives of La Plana (Castelló) has been used to obtain information about climate variability, including droughts, extreme rainfall, plagues and epidemics occurring around Castelló during the 1700's. Likewise, information upon the resources, both religious and secular, used to prevent firstly and later eradicate said climatic, biological and health hazards.
\end{abstract}

Keywords: Flooding, Droughts, Plagues, Hail, Epidemics, Castelló. 


\section{Introducción}

El debate sobre el cambio climático constituye un tema latente de la sociedad actual. Los efectos derivados del calentamiento global, así como la reiterada sucesión de acontecimientos naturales de carácter extraordinario, han generado una voluminosa literatura, tanto en el ámbito científico como en el de divulgación. Precisamente, este afán por conocer las transformaciones climáticas de nuestro presente ha propiciado un mayor interés por la climatología histórica puesto que el clima del planeta Tierra ha sido el escenario de constantes y notables variaciones a lo largo de su historia, que han condicionado al ser humano.

En esta línea, el presente artículo recurre a la microhistoria para analizar los archivos municipales de una determinada comarca valenciana -la Plana de Castelló- con el objetivo de obtener nuevas referencias sobre la evolución climática de la fachada mediterránea peninsular durante un periodo cronológico concreto: el siglo XVIII, enclavado en los estadios finales de la Pequeña Edad de Hielo. Con esta finalidad, el trabajo se inicia con una contextualización geográfica del caso estudiado, una crítica de las fuentes primarias y secundarias utilizadas y un resumen de las características climáticas más relevantes del País Valenciano durante el Setecientos. Abordamos después las principales sequías, precipitaciones extremas, plagas y epidemias acontecidas en la Plana de Castelló durante aquel siglo. Se analizan también los recursos, tanto religiosos como seculares, utilizados para prevenir, primero, y erradicar, después, las adversidades climáticas, biológicas y sanitarias.

\section{El área de estudio: La Plana de Castelló}

La Plana de Castelló es una extensa depresión sedimentaria triangular del Cuaternario situada en la desembocadura del río Millars, en las actuales comarcas de la Plana Alta y la Plana Baixa. Un espacio geográfico de 4.018 $\mathrm{km}^{2}$ rodeado por las sierras de Borriol, Espadà, Pedrisses, el desierto de las Palmas y el mar Mediterráneo ${ }^{1}$.

1. QUEREDA SALA, 1985: 53. 
Los efectos de la adversidad climática y sanitaria sobre la agricultura y la sociedad castellonense del siglo XVIII

El río más importante de la zona es, como ya hemos dicho, el Millars, caracterizado por Cavanilles como «la fuente de la abundacia de esta región» ${ }^{2}$. El transcurso del mismo nace en El Castelar (Teruel), a más de 1.500 metros de altura sobre el nivel del mar, y su caudal se enriquece con las precipitaciones registradas en las sierras de Gúdar, Javalambre y el Maestrat. En su recorrido cruza la comarca del Alt Millars y llega hasta la Plana, donde converge con sus afluentes: Albentosa, Villahermosa, Montant y la Rambla de la Vídua, aunque todos ellos son de escaso caudal. Cabe destacar también, la existencia de relevantes estiajes, que provocan, además, importantes oscilaciones en su caudal ${ }^{3}$.

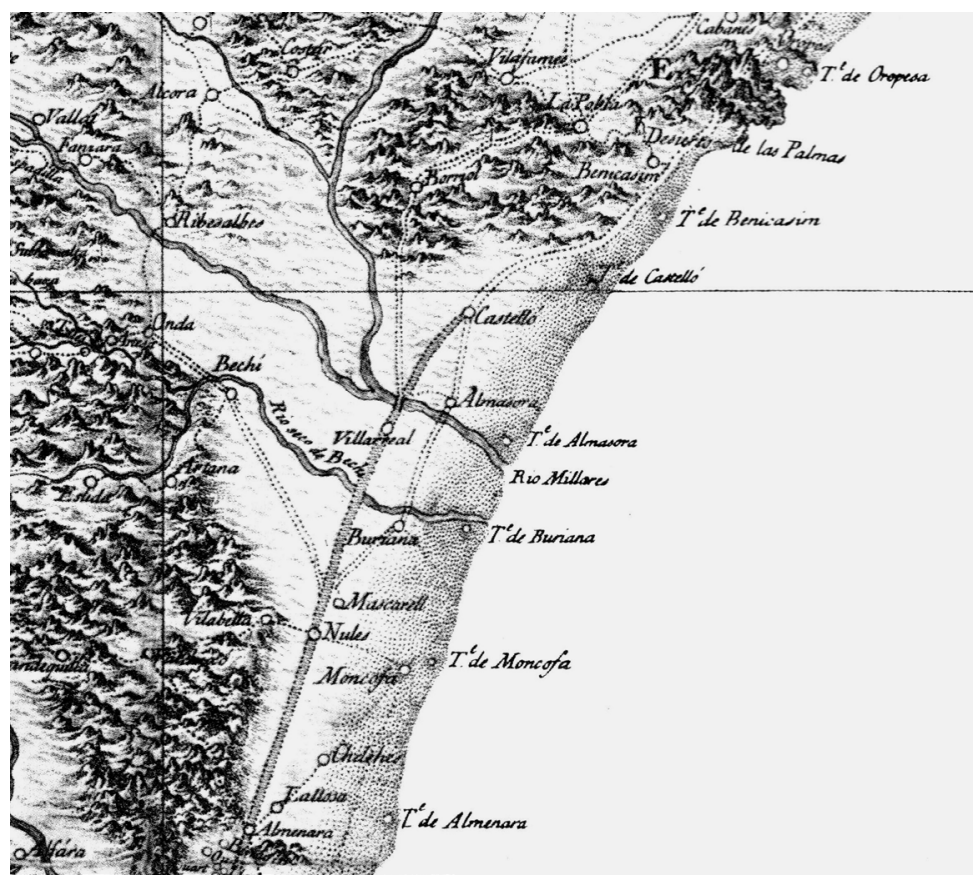

Imagen 1: La Plana de Castelló según Cavanilles ${ }^{4}$.

2. CaVANiLles, 1795, II: 100.

3. QUEREDA SALA, 1985: 81.

4. CAVANILLES, 1795, II: 100.

Revista de Historia Moderna, n. ${ }^{\circ} 35$ (2017) (pp. 410-438) | ISSN-e: 1989-9823 | ISSN: 0212-5862 
El clima de la Plana presenta, como es natural, las características propias del litoral mediterráneo. No obstante, como no existen datos estadísticos para el siglo XVIII, utilizaremos los registros del siglo XX para hacer una aproximación cuantitativa a sus características, aun siendo conscientes de que pueden no ser exactamente iguales en ambos periodos. De esta manera, podemos observar que en la Plana existe habitualmente una cierta escasez de precipitaciones, habiendo una media de 526,9 litros por $\mathrm{m}^{2}$ anuales ${ }^{5}$. Esta carencia se manifiesta sobre todo en el verano, siendo el mes de julio el más seco de todos con 9,1 litros por $\mathrm{m}^{2}$ de media anual ${ }^{6}$. Esta escasez estival contrasta con los meses equinocciales, momento en que las precipitaciones aumentan, aunque, muchas veces, concentradas en unos pocos días.

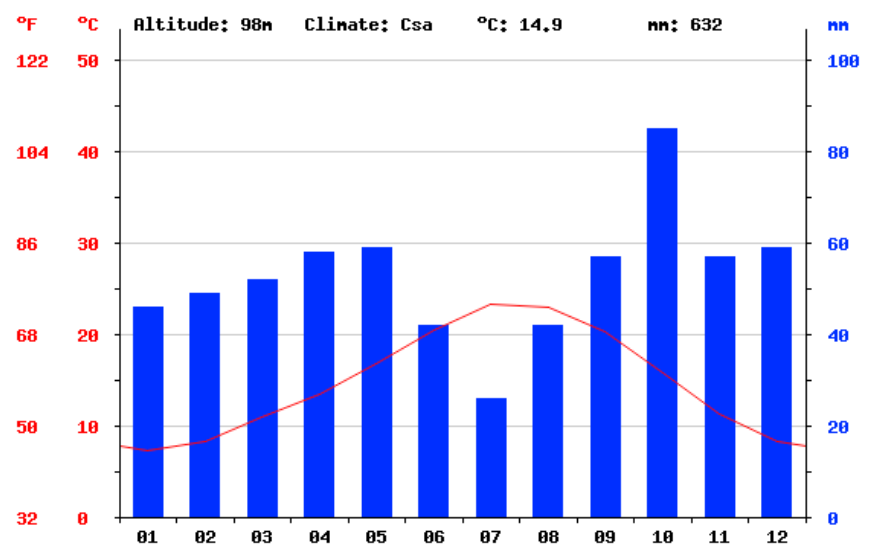

Gráfica 2. Climograma de Castelló de la Plana.

Por lo que se refiere al paisaje humano durante el siglo XVIII, la Plana de Castelló contaba con tres espacios agrarios claramente diferenciados: al este se encontraba el regadío o las huertas, que contaba con la posibilidad física y el derecho histórico de ser regadas por las aguas del río; al oeste estaba el

5. QUEREDA SALA, 1985: 62.

6. Ibídem.

7. http://es.climate-data.org [consultado el 13-8-2014]. 
secano, normalmente formado por un suelo de peor calidad y sin posibilidad legal y material de ser irrigado; finalmente, junto al litoral se encontraban los marjales, resultado de la bonificación de humedales ${ }^{8}$. Los regadíos de la Plana contaban desde la Baja Edad Media con cinco instituciones de riego (Castelló, Vila-real, Borriana, Almassora y Nules), gobernadas y gestionadas por sus correspondientes corporaciones municipales. Esta característica dio lugar a una fuerte asimilación entre municipio y comunidad de regantes, circunstancia que dota a cada villa de cierta identidad propia, acompañada de fuertes tensiones con los pueblos vecinos.

Por lo que se refiere al paisaje agrario de la Plana en el Setecientos, destacaban sus campos abiertos con policultivo, siendo plantados tanto cultivos de orientación comercial como de subsistencia. Por lo que se refiere a los primeros, cabe referenciar los algarrobos - utilizados como forraje para los animales-, las moreras -para el comercio de la seda-, o el cáñamo -para la confección de ropa, cuerdas, sacos, alpargatas, redes de pesca...-, sin olvidarnos de los olivares, las viñas - no solo cultivadas para la elaboración de vino sino también de aguardiente-y las higueras - explotadas principalmente en el interior de la comarca- ${ }^{9}$. Igualmente importante, fue el cultivo de los cereales y las leguminosas en los regadíos, puesto que conseguían allí unos rendimientos muy superiores a los del secano, sin significar su pervivencia un síntoma de atraso $^{10}$.

\section{El legado historiográfico y las fuentes de estudio}

Si bien es cierto que, hasta la fecha, la Plana de Castelló no ha suscitado monografías sobre su evolución medioambiental durante el siglo XVIII, no podemos olvidar que en las universidades valencianas existe una consolidada línea de trabajo que, encabezada por Armando Alberola y el Grupo de Investigación en Historia y Clima de la Universitat d'Alacant, ha posibilitado el estudio detallado de las condiciones climáticas y el análisis de las series históricas instrumentales de datos meteorológicos, así como la investigación de los episodios meteorológicos de rango extraordinario, el análisis de las relaciones

\footnotetext{
8. GARrido Herrero, 2004: 17.

9. Garrido Herrero, 2004: 44-90. Membrado Tena, 1995.

10. GARRABOU SEgura, 1985.
} 
existentes entre la climatología de situaciones adversas y la agricultura o el estudio de la religiosidad popular a través de las rogativas.

En definitiva, existe un legado historiográfico de más de dos décadas sobre la evolución medioambiental de las tierras de la fachada mediterránea que facilita la interpretación de las fuentes primarias castellonenses. Estas fuentes pertenecen principalmente a tres archivos municipales. En el Archivo Municipal de Castelló, se custodia una serie muy completa de Libros de Actas que dan constancia de las principales adversidades medioambientales, el precio anual del trigo o las rogativas. Esta información se complementa con el Llibre Vert, un manuscrito donde, desde el siglo XVII, se anotaron algunos de los sucesos más destacados de la localidad. Junto a él cabe destacar los fondos Aguas, Memoriales y Reales Cédulas y Decretos, ambos de gran volumen y de extraordinaria variedad de contenido. El Archivo Municipal de Vila-real, por su parte, cuenta con doce Libros de Actas y veinticinco Judiciarios. Entre sus fondos destaca además el del Jurista Llorens, donde hay custodiados una decena de documentos útiles para la elaboración de este trabajo. En tercer lugar, tenemos el Archivo Municipal de Nules, que es cuantitativamente inferior a los anteriores, puesto que solo conserva algunos documentos con referencias medioambientales aisladas. Finalmente, es interesante complementar estos archivos municipales con los parroquiales, donde podemos obtener información sobre bautizos, entierros y matrimonios en Borriol, Betxí, Cabanes, Castelló de la Plana, la Llosa, Mascarell, Nules, Orpesa, la Serra d'En Galceran, Vila-real o Vilafamés ${ }^{11}$.

Estas fuentes primarias son combinadas, a su vez, con los comentarios de los cronistas castellonenses de los siglos XVIII, XIX y principios del XX. El más importante de ellos tal vez sea el fraile agustino José Rocafort, quien, siendo coetáneo a los hechos, escribió a finales del Setecientos un diario llamado Libro de cosas notables de la villa de Castellón de la Plana ${ }^{12}$. Ya en el Ochocientos destaca la figura del bibliotecario y político Juan Antonio Balbás, quien escribió dos obras reseñables para esta investigación El libro de la Provincia de Castellón ${ }^{13}$, donde hace una recopilación de efemérides, y

\footnotetext{
11. BERNAT MARTí, 1996.

12. ROCAFORT, 1945.

13. BALBÁS, 1892.
}

Revista de Historia Moderna, n. ${ }^{\circ} 35$ (2017) (pp. 410-438) | ISSN-e: 1989-9823 | ISSN: 0212-5862 
La Virgen del Lidón ${ }^{14}$. Junto a Balbás también debe ser citado el notario Lluís Bellver y su crónica Historia de Castellón de la Plana ${ }^{15}$. Finalmente, a principios del siglo XX destacan las obras de los vila-realenses, mosén Benito Traver y mosén Juan Bautista Candau. El primero, miembro de Lo rat penat, por escribir dos obras al estilo de la «Renaixença», tituladas Historia de Villarreal y Efemérides de Villarreal $^{16}$, y el segundo por su libro La gracia en Villarreal: memoria histórico-descriptiva de la Imagen y Culto de Nuestra Señora de Gracia venerada en la ciudad de Villarreal ${ }^{17}$, donde se narran los supuestos milagros de esta virgen en respuesta a las rogativas.

\section{Las características climáticas del País Valenciano durante el siglo XVIII}

Para comprender con claridad los diferentes episodios meteorológicos adversos del siglo XVIII, es imprescindible contextualizar esta centuria dentro de un periodo climático más amplio y de gran relevancia: la Pequeña Edad de Hielo $(\mathrm{PEH})^{18}$. En efecto, desde el segundo tercio del siglo XIV, hasta mediados del XIX, el clima europeo cambió en pro de una mayor inestabilidad y una temperatura media mucho más baja en comparación con el Período Cálido Medieval (700-1300 aprox.). En este sentido, se combinaron los duros inviernos y las precipitaciones torrenciales de los meses equinocciales, con inviernos más suaves y veranos extremadamente secos. Dicho esto, el Siglo de las Luces debe ser situado en los estadios finales de la $\mathrm{PEH}$, puesto que se experimentó una cierta recuperación térmica respecto al siglo anterior, aunque conservando otra de las características de la PEH: la acentuada variabilidad climática ${ }^{19}$.

Así pues, hay que destacar que el siglo XVIII tuvo, a su vez, dos pulsaciones de frío intenso: el mínimo de Maunder (1645-1715) y la oscilación o anomalía Maldà (1760-1800) ${ }^{20}$. Pese a esto, es relevante señalar que, en líneas generales, durante gran parte del Setecientos, el País Valenciano vivió casi permanentemente en estado de sequía, aunque esto siempre estuvo contrastado

\footnotetext{
14. BALBÁS, 1890.

15. BELLVER, 1888.

16. Traver García, 1909. Traver García, 1935.

17. Candau, 1907.

18. Véase: Le Roy Ladurie, 1991. Alberola Romá, 2014.

19. Alberola Romá, 2010: 59.

20. Alberola Romá, 2014: 22.
}

Revista de Historia Moderna, n. ${ }^{\circ} 35$ (2017) (pp. 410-438) | ISSN-e: 1989-9823 | ISSN: 0212-5862 
con las grandes avenidas periódicas de los ríos y las fatales consecuencias que ello conllevaba ${ }^{21}$. Estos contrastes se vieron especialmente acentuados en el último cuarto de siglo, y aún más especialmente en las décadas de 1770 y 1780 , con la ya mencionada anomalía Maldá22. Fue en aquellos momentos cuando se experimentó una acentuación en la alternancia entre las inundaciones y las sequías, a la par que se percibió una acusada oscilación térmica y una pluviometría catastrófica ${ }^{23}$. Junto a las inundaciones y las sequías, el siglo XVIII experimentó también otras adversidades climáticas como las heladas y los pedriscos, sin olvidarnos de otras dificultades de índole biológica y sanitaria como las plagas y las epidemias. Todas ellas son objeto de estudio de este trabajo.

\section{Las sequías y la escasez de trigo}

El siglo XVIII fue, como ya hemos dicho, una centuria donde la escasez de precipitaciones fue una constante más allá de los episodios de pluviosidad extrema que describiremos más adelante. Estas sequías, son muy importantes para el estudio de las sociedades rurales valencianas, porque acentúan las tensiones entre regantes y condicionan negativamente la producción, siendo especialmente documentados los daños en trigo y cáñamo, puesto que en Castelló este último era el cultivo con más proyección durante el Setecientos.

Las primeras noticias sobre la escasez de agua en la Plana datan de 1720, momento en que el ayuntamiento de Castelló se percataba de la necesidad de «tomar medidas, más este tiempo en que tanto se necesita de el agua» ${ }^{24}$; seguidamente, en marzo de 1725 las predicciones de cosecha de trigo eran muy negativas ${ }^{25}$, y no era para menos, puesto que, cinco meses después, la sequía era tal, que dicho consistorio limitó el cultivo de cáñamo en la partida Ramell, puesto que la práctica de «hacer muchos cáñamos (...) en el mismo campo 2 años continuos» agravaba la «necesidad de agua» ${ }^{26}$. Los efectos de

21. Alberola Romá, 2010: 96.

22. BARRIENDOS VALLVÉ y LLASAT BOTIJA, 2009: 253-286.

23. Alberola Romá, 2010: 60-63.

24. Archivo Municipal de Castellón (en adelante AMC). Sesiones de Ayuntamiento, núm. 9. 25. AMC. Sesiones de Ayuntamiento, núm. 1, (09-03-1725).

26. AMC. Sesiones de Ayuntamiento, núm. 1, (24-07-1725). 
la misma son igualmente significativos al año siguiente, puesto que en el mes de febrero el ayuntamiento insistía en la «gran carestía y necesidad de agua» ${ }^{27}$, motivo por el cual se llevó la imagen del Santo Sepulcro hasta la iglesia mayor para celebrar rogativas ${ }^{28}$. En 1729 , la cosecha de trigo fue muy mala, de modo que, en noviembre, se adoptaron medidas a favor de la limitación de venta de trigo a «forasteros», sin consentimiento previo del consistorio, bajo pena de 3 libras y el «trigo perdido» ${ }^{29}$.

Durante los años treinta, la escasez de agua y de cosechas fue una constante, aunque esta vez acompañadas por las epidemias. Así pues, en 1730 la dura epidemia de catarros convivió durante el mes de abril con la «gravísima necesidad de agua por la falta de lluvias [que] agrava la enfermedad $»^{30}$. Una situación de extrema urgencia, que se trató de solucionar mediante una procesión de la Virgen del Lidón y las correspondientes rogativas en Castelló. Aunque llovió torrencialmente en 1732, nada cambió. En marzo de 1733 el ayuntamiento de Vila-real compró trigo a dos particulares «para que no falte el abasto de la villa» ${ }^{31}$, mientras que, en julio de 1736, se confirmó que la cosecha de trigo había sido especialmente corta ese año ${ }^{32}$.

Fue precisamente en este contexto de escasez hídrica, cuando, en 1731, José Castell Museros propuso al ayuntamiento de Castelló que se pidiera a la Corona un privilegio real para que el municipio pudiera beneficiarse de las aguas de la Rambla de la Vídua ${ }^{33}$. Con tal objetivo se presentó un memorial a Felipe $\mathrm{V}$ explicando que esta infraestructura hídrica fomentaría la riqueza de una población en aumento y, con ello, una mayor capacidad de pagar los tributos $^{34}$. Tras una consulta con Vilafamés -municipio también interesado en el aprovechamiento de las aguas de dicha rambla-y, la elaboración de un

27. AMC. Sesiones de Ayuntamiento, núm. 1, (06-02-1725).

28. BALBÁS, 1892: 426.

29. AMC. Sesiones de Ayuntamiento, núm. 1, (30-09-1729).

30. AMC. Sesiones de Ayuntamiento, núm. 2, (19-04-1730).

31. Archivo Municipal de Vila-real (en adelante AMVr) Judiciario del año 1733, (06-03-1733).

32. AMVr. Judiciario del año 1736, (17-07-1736).

33. Véase: Gimeno Michavila, 1935.

34. AMC. Aguas, caja 12, núm. 74. Súplica de la Villa de Castellón al rey para que se le conceda el uso de las aguas de la Rambla de la Viuda, s/n. 
informe pericial sobre las obras necesarias ${ }^{35}$, Castelló conseguiría el privilegio en 1747 , aunque, sin poder llegar a materializarlo debido a las dificultades de financiación.

En los años cuarenta, aunque no se han encontrado referencias directas a la sequía, sí hay muchas a la escasez de trigo. En marzo de 1747, el ayuntamiento de Castelló hizo «averiguaciones para prevenir la escasez de trigo», puesto que llevaban varios meses advirtiendo que les podría llegar a faltar. Dos años después, la situación parece ser aún más crítica y vuelve a regularse la venta de trigo a forasteros, previo aviso a las autoridades, con la novedad de que ahora también se regula la del panizo "por la carestía» ${ }^{36}$. Igualmente destacables son las restricciones a los molinos harineros, a los que se les obligó a no moler más de 4 barchillas sin permiso y no vender a forasteros ${ }^{37}$.

No obstante, ante tanto esfuerzo por regular la venta de trigo y panizo, y tantas prevenciones para que «este común no llegase al caso de experimentar la [...] falta de este abasto», lo cierto es que existen evidencias de que los castellonenses cometían «fraudes sobre extracción de trigo (...), respecto que los vecinos, con el pretexto de hir ha moler, beneficiaban a muchos forasteros sacando dicho trigo de la villa para muchos lugares $»^{38}$. Esta paradoja, escasez-fraude, podría ser explicada si tenemos en cuenta que las sequías no desestabilizaron el precio del trigo en estos momentos, es decir, no coincide ninguna subida del precio con los años especialmente secos. Y es que Castelló contaba con unas sólidas redes de aprovisionamiento con Morella, Aragón y Catalunya a las cuales se alude frecuentemente en la documentación. Estamos evidenciando, pues, que, aunque las sequías mermaran la producción durante muchos años, los sistemas de abastecimiento funcionaban a la perfección. Un buen abastecimiento que complemente la producción local de cultivos de subsistencia es fundamental para favorecer la consolidación de algunos cultivos de orientación comercial, como el cáñamo en Castelló o la vid en

35. AMC. Aguas, caja 14. núm. 81. Informe pericial emitido por Pedro Juan de la Viesca Forte, arquitecto, y Miguel Bueso sobre la conducción de aguas de la Rambla de la Viuda (1732).

36. AMC. Sesiones de Ayuntamiento, núm. 5, (15-01-1749 y 22-01-1749).

37. AMC. Sesiones de Ayuntamiento, núm. 5, (15-02-1749 y 18-02-1749).

38. AMC. Sesiones de Ayuntamiento, núm. 5, (18-02-1749). 
Vila-real para elaborar aguardiente, sin olvidarnos de otros como la morera y el algarrobo.

Todos estos datos, referentes a sequías y pérdidas en la producción de trigo local, pueden tener una especial relevancia para entender las causas de los dos mayores picos de mortalidad que sufre Castelló en la primera mitad del siglo, ya que se alcanzaron 573 enterramientos en 1725 y 597 en 1748, cuando la media entre 1698 y 1754 fue de 311 anuales. Esto adquiere especial relevancia si tenemos en cuenta que en los dos casos el $78 \%$ de los enterrados fueron registrados como «niños y niñas» ${ }^{39}$. Estos datos podrían estar relacionados con una hipótesis de Moreno Almárcegui, según la cual las largas sequías y los fuertes calores favorecían la difusión de enfermedades del aparato digestivo. Éstas provocaban-especialmente entre los menores de 4 años- diarreas, deshidratación y muerte prematura.

Otra consecuencia de este periodo de escasez hídrica, está relacionada con el aparente empeoramiento de los niveles de vida de la población durante estos años, motivo por el cual el ayuntamiento pidió, en 1740, que se rebajaran ciertos impuestos ${ }^{40}$, ya que, según él, Castelló «tiene muchos vecinos» y «ay gran parte de ellos fallidos y sumamente pobres que no pueden contribuir en el reparto del Equivalente y dejan de pagar», razón por la cual se «carga en los demás» ${ }^{41}$.

En las décadas de los cincuenta y sesenta, la situación siguió siendo dura. Corría el año 1750, cuando el consistorio de Castelló decidió empezar a tomar medidas para ahorrar trigo en los hospitales, ahora se prefería que los enfermos «pobres y miserables» no fueran allí, a cambio de entregarles una compensación de media ración de trigo diaria, siendo esta ración menor a la que consumirían en el hospital ${ }^{42}$. Dos años después continuaron las restricciones a la venta de trigo a forasteros ${ }^{43}$ y, en 1756, los Libros de Actas hablan de que «por la mucha escasez de agua no se habían podido regar muchas de

39. Archivo Parroquial de Santa María (en adelante APSM), Libro de Bautizos, núm. 11 y 13. 40. En aquellos momentos Castelló pagaba 11.660 libras más el cuatro por ciento de «trabajos de cobranza».

41. AMC. Sesiones de Ayuntamiento, núm. 2, (19-04-1730).

42. AMC. Sesiones de Ayuntamiento, núm. 5, (18-07-1750).

43. AMC. Sesiones de Ayuntamiento, núm. 5, (02-03-1752). 
las tierras» ${ }^{44}$, al igual que en 1769 , momento en que se convocó a todos los prohombres de las partidas de regadío para «tratar y conferir la necesidad (...) de aguas» ${ }^{45}$.

En los años setenta la oscilación Maldá es más que visible. En 1770, se alude a la «necesidad de aguas que tenían los campos cembrados», puesto «que estuvieron sin regarse durante todo el mes de marzo y desde abril hasta pasado julio, damnificándose especialmente la siembra de cáñamo» ${ }^{46}$.

Estas circunstancias generaron tensiones entre los regantes, y sobre todo el incumplimiento de las normas del riego, ya que algunos ensancharon la acequia de Fadrell más de lo permitido, al igual que se manipuló el hilo de la Plana un año después ${ }^{47}$. Los problemas llegaron incluso a afectar a la vida cotidiana de los castellonenses, puesto que «en el arrabal de San Francisco no hay agua para la manutención de sus vecinos» ${ }^{48} \mathrm{y}$ al menos cinco «pozos manantiales» estaban $\sec \cos ^{49}$. La respuesta por parte de los castellonenses fue la celebración de rogativas en 1770 y 1771, pero, aunque llovió torrencialmente durante los dos años, no se acabó con el problema de fondo, de manera que, en 1772, aún había «mucha escasez de agua, pasando en el verano diez, doce semanas sin poder regar $»^{50}$.

Tras estos tres años de extrema dureza, las referencias documentales a sequías ya no son tan abundantes, aunque no por ello menos importantes. En 1776, 1793 y 1798 volverían a celebrarse rogativas por este motivo ${ }^{51}$ y en 1792 destaca la carta que la Junta de Regantes de Castelló envió al ayuntamiento para «que se tomen medidas para paliar la escasez de agua», puesto que «persuaden que el principal origen de su falta nace de la nutrición del partidor de las aguas del río Mijares, adverado el perjuicio en todas las medidas, que cada día se están haciendo a instancia de la villa de Borriana» ${ }^{52}$.

44. AMC. Sesiones de Ayuntamiento, núm. 6, (1756).

45. AMC. Aguas, caja 14, s/n.

46. AMC. Sesiones de Ayuntamiento, núm. 9, (05-03-1770, 12-07-1770 y 18-07-1770).

47. AMC. Sesiones de Ayuntamiento, núm. 9, (09-07-1770).

48. AMC. Sesiones de Ayuntamiento, núm. 9, (22-10-1770 y 01-07-1771).

49. AMC. Sesiones de Ayuntamiento, núm. 9, (11-03-1771 y 21-09-1771).

50. AMC. Sesiones de Ayuntamiento, núm. 9, (12-08-1772).

51. BALBÁs, 1892: 421. LORES, 1999.

52. AMC. Aguas, s/n. 
Los efectos de la adversidad climática y sanitaria sobre la agricultura y la sociedad castellonense del siglo XVIII

\section{Las precipitaciones extremas}

Aunque, como hemos visto, la escasez de agua tuvo un papel muy destacado en el siglo XVIII, las rogativas pro pluvia se alternaban, a menudo, con las rogativas pro serenitate debido a las precipitaciones extremas que podían caer en los meses equinocciales. Como veremos, los desbordamientos de los ríos, las inundaciones de los campos o los pedriscos también perjudicaban la producción agraria, aunque, a diferencia de las sequías, éstas fueron mucho más casuales hasta la década de 1760, cuando, a partir de la oscilación Maldá, se produjeron con mucha mayor frecuencia. Junto a los perjuicios en la producción, también hay que señalar los daños materiales que estos episodios meteorológicos ocasionaban.

Con anterioridad a la oscilación Maldá cabe destacar la inundación de 1732. Ésta arruinó el trazado de la Acequia Mayor de Castelló, así como las de Mediona y Coscollosa ${ }^{53}$. Por tal motivo, el acequiero mayor de la capital de la Plana, Severino Pascual, elevó cuatro memoriales al ayuntamiento con el objetivo de dejar constancia de los desperfectos ocasionados por el agua y los gastos necesarios para las reparaciones pertinentes. Estos memoriales constituyen una fuente excelente con los que ejemplificar el proceso de limpieza de una acequia comunal durante el siglo XVIII.

De este modo, Severino expuso que, para el caso de la acequia de Coscollosa, los gastos habían ascendido a 14 libras, 3 sueldos y 8 dineros, puesto que fue necesario cuatro días de trabajo para «sacar arena, piedras y demás enrunia», a razón de 4 sueldos por hombre y día trabajado, sumándole las dietas del acequiero (1 libra y 12 sueldos) y el bagaje necesario para abastecer de alimento a los trabajadores (10 sueldos) ${ }^{54}$. Muy semejante fue lo ocurrido en la acequia de Mediona, en este caso los gastos fueron de 11 libras y 1 sueldo, siendo necesario el pago de 37 jornales a razón de 1 sueldo y 6 dineros por hombre y día trabajado, sin olvidarnos de las dietas del acequiero y el equipamiento pertinente ${ }^{55}$. Finalmente, por lo que respecta a la Acequia Mayor, el trabajo se hizo sobre el margen, a la altura de los partidores reales. De este modo, los gastos ocasionados por la limpieza de la arena y los

53. AMC. Aguas, núm. 80 y 81.

54. AMC. Aguas, núm. 80.

55. AMC. Aguas, núm. 81.

Revista de Historia Moderna, n. ${ }^{\circ} 35$ (2017) (pp. 410-438) | ISSN-e: 1989-9823 | ISSN: 0212-5862 
escombros ascendieron hasta las 20 libras y 7 sueldos, destacando para este caso el uso de «hachillas» por parte de los trabajadores contratados.

Un episodio similar sucedió en noviembre de 1766, cuando en Borriana, «con las avenidas continuadas del río en este invierno, ha ocurrido terraplenarse la azequia Mayor, arruinándola enteramente, y siendo preciso sacar todo el cascajo o grava que havía acarreado el río $»^{56}$. Esta misma avenida provocó que en Castelló se rompiera el almacén de la sal $^{57}$ y se celebraran rogativas $^{58}$. Seis años después, en los meses de septiembre y noviembre de 1771 , se volvieron a ocasionar «muchas ruinas» en las acequias de Castelló «por las avenidas de aguas», dándose orden de ser reparadas ${ }^{59}$.

La oscilación Maldá ya estaba más que presente en el litoral valenciano y, bajo este contexto climático, 1775 fue un año especialmente destacable, puesto que en él se dio cabida a tres grandes episodios de precipitaciones extremas. El primero se produjo en enero, cuando hubo «siete días seguidos de continuas lluvias y recio temporal», el cual «hundió muchas casas, derrumbó paredes y anegó los campos, convirtiendo el término en un mar y las calles en ríos de agua que llegaba hasta las casas» ${ }^{60}$ de Vila-real. El segundo tuvo lugar durante el mes de junio, cuando un «temporal de lluvias» puso en gran peligro «la cosecha de trigo, que ya tenía la caña podrida y negra», puesto que, a causa de las lluvias, no podía ser segado ${ }^{61}$. Finalmente, la última tempestad del año se produjo el 31 de septiembre, momento en que los campos de Vila-real quedaron completamente inundados y «una de las acequias mayores (...) sufrió tal estrago por el ímpetu de las aguas, que, sin embargo, de estar fortalezida con pared de buen material la harruinó absolutamente por siete partes y por otras más está a punto de caerse, desaguando por ellas en los campos vecinos» ${ }^{62}$.

Por si estos temporales de fuertes lluvias no hubieran sido lo suficientemente perjudiciales, durante 1776 se experimentaron dos acontecimientos

56. Archivo Municipal de Nules (AMN), Aigues, caja Siglo XVIII, s/n.

57. AMC. Reales cédulas y decretos, caja 1. s/n.

58. LORES, 1999: 199.

59. AMC. Aguas, caja 14, s/n y Sesiones de Ayuntamiento, núm. 9, (17-10-1771).

60. CANDAU, 1907: 94.

61. Ibídem.

62. AMVr. Jurista Joaquín Llorens. 9621/1775. 
igualmente reseñables por su gravedad. Nos estamos refiriendo al pedrisco caído durante el mes de junio y a las inundaciones de octubre. Por lo que se refiere al granizo, hay que destacar los muchos perjuicios que causó en la huerta de Vila-real «arrebatando las cosechas, destruyendo los árboles y arrancando una infinidad de ellos ${ }^{63}$. Los destrozos de esta tempestad fueron de tal magnitud que un grupo de labradores se dirigió a las autoridades municipales para que éstas pidieran a la Corona «un alivio equivalente a tan reiterados perjuicios» ${ }^{64}$. Para tal fin, se nombró a 19 expertos «de recta conciencia y experiencia acreditada (...), e inteligencia y buena conducta ${ }^{65}$, quienes, representando a las villas de Vila-real, Castelló, Almassora y Nules evaluaran los daños correctamente ${ }^{66}$. Una vez efectuado el peritaje, los expertos se reunieron en el ayuntamiento de Vila-real con el alcalde de este municipio, Joaquim Mundina Roig y, bajo juramento, se cuantificaron los daños. Como consecuencia de esta petición, el día 30 de agosto el intendente general decretó un repartimiento de 2.025 pesos, procedentes de la mitad del equivalente de 1776 para compensar los daños «que ocasionó la tempestad de piedra y agua (...) entre aquellos vecinos y terratenientes que padecieron dichos daños en sus heredades ${ }^{67}$. Este reparto se efectuó en relación a la cantidad de tierra que poseían.

Paralelamente a esta medida, el 14 de junio se publicó un bando en Vilareal «para que todo vecino que tuviese algún árbol arrancado de los comprendidos en dicha real ordenanza, como son chopos, nogales, las encinas y álamos negros y blancos» ${ }^{68}$ comunicaran al ayuntamiento los daños ocasionados.

\section{Ibídem.}

64. Ibídem.

65. Ibídem.

66. AMVr. Jurista Joaquín Llorens. 9622/1776. Los elegidos por parte de Vila-real fueron Lorenzo Climent maior (76 años), Manuel Monfort (76 años), Jaime Petit maior (54 años), Pascual Sancho y Fuente (59 años), Llorenzo Gil maior (54 años), Manuel Broch de Llorenç (50 años), Juan Martínez (45 años), Vicente Carda de José (54 años), Antonio Serrano de Martín (44 años). Por parte de Castelló Esteban Alonso (50 años) y Juan Navarro (75 años). Por parte de Almassora fueron Pedro Rovira (55 años) y Josep Grifo. Y por parte de Borriana fueron Blas Dandí (67 años) y Bautista Martí Navarro (41 años).

67. AMVr. Hacienda. 1628/1776.

68. AMVr. Familia Llorens. 9623/1776. 
Después de que se hiciera una relación de propietarios afectados por la caída de nogales ${ }^{69}$, el alcalde determinó que muchos de éstos «son buenos para fábricas de navíos» ${ }^{70}$, siendo este el motivo por el que se dio permiso a «los celadores de montes», ${ }^{71}$ José Galindo, menor, y José Almela Blasco, para que trataran de sacarle provecho a su madera. Tras la revisión de los árboles, se determinó que «solo hay uno que pueda servir para fábrica de naves, que es de nogal derribado en tierra de Joaquín Cubero, y que los demás los reputan por inútiles, y por ello se les puede dar facultad a los respectivos dueños para que puedan usar de ellos como les convenga ${ }^{72}$.

Una vez superados los infortunios de junio, los labradores castellonenses tuvieron que ver cómo un nuevo ciclo de fuertes precipitaciones perjudicaría sus campos entre el 21 y el 24 de octubre del mismo año. En esta ocasión, la principal damnificada fue la villa de Castelló. El día 22 hubo una «horrible tempestad de truenos, relámpagos y especialmente de agua, que parecía bolver otra vez el diluvio», el cual derribó algunas casas e inundó la huerta hasta el punto de que «pareciese un nuevo mar». Otros daños destacables fueron los experimentados en el huerto y el pozo del convento de los agustinos, así como en las acequias, que cedieron debido a que el agua «excedía sobre el canal (...) de Coscollosa, hasta la altura de 6 palmos». Entre la noche del día 23 y la madrugada del 24, Pascual Viciano murió alcanzado por un rayo, el río volvió a salirse de su cauce y muchas casas de Castelló se derrumbaron. Finalmente, durante la mañana del día 26 "parecía averse de acabar el mundo con los fuertes y continuados truenos, relámpagos y agua y muy recio ayre, como de un uracán, el más veloz», recurriéndose a la celebración de rogativas ${ }^{73}$.

Como puede deducirse, las inundaciones de octubre causaron importantes daños humanos y materiales. Una catastrófica situación que no se

69. Los damnificados fueron: con un nogal, Pascual Agelsinona (sic), Tomàs Albiol, Tomás Almela, Joaquím Amer, Tomás Añejo, Manuel Broch, José Cabrera, José Carda, Pedro Conde, Tomás Costa, Juan Manrique, Miguel Marí, Féliz Melchor, Blas Moner, Moner, Lorenzo Moner, Tomás Monfort, José Nacher, Domingo Nebot, José Nebot, Pascual Notari y José Ortiz; con dos nogales, Tomás Broch; y con un nogal y un chopo, Tomás Avellot.

70. AMVr. Familia Llorens. 9623/1776.

71. Ibídem.

72. Ibídem.

73. ROCAFORT, 1945: 41-42. 
Los efectos de la adversidad climática y sanitaria sobre la agricultura y la sociedad castellonense del siglo XVIII

materializó de forma aislada en la Plana, sino que también tuvo efectos similares a lo largo del territorio valenciano. Recordemos que fue precisamente en 1776 cuando se produjo uno de los más conocidos desbordamientos del río Turia a su paso por Valencia ${ }^{74}$.

Tras estas catástrofes, cabe destacar los acontecimientos de 1783, puesto que hubo una atípica primavera con bajas temperaturas provocadas por la erupción del volcán islandés Laki, el cual ocasionó en Castelló «una densísima niebla que duró varios días y causó gran pavor a las gentes» ${ }^{75}$, «una especie de niebla seca, que oscurecía el sol, de tal modo que iluminaba muy poco y esto duró hasta la mitad de junio ${ }^{76}$. Lejos de la anécdota, este hecho estuvo acompañado por una subida del precio del pan en junio ${ }^{77}$, y tres fuertes tempestades -en septiembre, octubre y diciembre- que no solo perjudicaron las aceitunas y algarrobas que estaban colgando de los árboles ${ }^{78}$, sino que anegó la huerta hasta el punto de que los «agricultores no pueden cultivar ni trabajar sus campos ${ }^{79}$. En palabras de Rocafort, «desde la mar casi la mitad de la huerta era todo una laguna ${ }^{80}$. Junto a estos daños agrarios, hubo diferentes hombres y caballerías que murieron ahogados en el Millars y la Rambla de la Vídua, el correo se vio interrumpido ${ }^{81}$, el matadero de la carnicería sufrió desperfectos ${ }^{82}$ y las «fiestas de toros en las calles» fueron suspendidas ${ }^{83}$.

En octubre de 1787 una tempestad ocasionó el derrumbe de puentes y molinos en Onda y Atzeneta del Maestrat ${ }^{84}$, así como el desborde del Millars, inundando el puente de Santa Quitèria entre Vila-real y Almassora ${ }^{85}$. Un mes después, una nueva inundación ocasionaría tales desperfectos en los molinos

74. Sobre las inundaciones del Turia de 1776 véase: FAUS PRIETO, 65-66 (1999): 132-142. Alberola Romá, 23, (2005). Alberola Romá, 2010: 125-163.

75. BALBÁS, 1892: 482.

76. ROCAFORT, 1945: 49.

77. AMC. Sesiones de Ayuntamiento, núm. 10, (12-06-1783).

78. AMC. Sesiones de Ayuntamiento, núm. 10, (15-09-1783).

79. AMC. Sesiones de Ayuntamiento, núm. 10, (10-11-1783).

80. ROCAFORT, 1945: 49-50.

81. Ibídem.

82. AMC. Sesiones de Ayuntamiento, núm. 10, (16-10-1783).

83. AMC. Sesiones de Ayuntamiento, núm. 10, (23-10-1783).

84. ROCAFORT, 1945: 53.

85. BALBÁS, 1892: 872 .

Revista de Historia Moderna, n. ${ }^{\circ} 35$ (2017) (pp. 410-438) | ISSN-e: 1989-9823 | ISSN: 0212-5862 
harineros de Castelló que desencadenaría una escasez de pan en la ciudad ${ }^{86}$. Las inundaciones de 1787, son transcendentales, puesto que marcaron un punto de no retorno en las pretensiones de esta localidad a la hora de construir la Acequia Nueva. Así pues, una vez cesadas las lluvias, los castellonenses observaron que el agua del río no llegaba hasta su huerta, de manera que, con la idea de que la tormenta habría obstruido la captación de este recurso natural, «se arrimaron a concurrir con sus carros, caballerías y brazeros a la reparación del azut de dicho Mijares» ${ }^{87}$. Una vez allí, se dieron cuenta de que, en realidad, el problema no era de origen natural, sino humano. Tras la inundación, sus vecinos de Almassora, con quienes compartían el azud y los primeros kilómetros de acequia, habían provocado intencionadamente una obstrucción de las aguas para que estas no llegaran a Castelló.

Tras la nevada de 1788, durante la cual se helaron las acequias de la misma localidad $^{88}$, se produjeron nuevas inundaciones en 1791 y 1792, de la cuales solo sabemos que causaron «daños inmensos en los campos» ${ }^{89} \mathrm{y}$ «estragos en la huerta $»^{90}$ de Castelló.

Al año siguiente la situación fue mucho más complicada a causa de la existencia de dos grandes tempestades. La primera, «parecía un diluvio» y aconteció durante el 6 y el 8 de septiembre de 1793, ocasionando atrasos en el correo y grandes desperfectos materiales en la Puerta del Olmo de Castelló y el convento de los agustinos, en donde «avía tanta agua que entrava en algunas celdas y (...) no se podía passar a la sacristía», además de inundarse el claustro, la capilla de Gracia y «muchas sepulturas» ${ }^{91}$. Los daños se vieron también en los campos de cultivo, puesto que inundó las huertas. Junto a la lluvia, cabe destacar los daños ocasionados por el pedrisco, ya que «destrozó frutas y hortalizas y cáñamo ya recogido» y «no dexó aluvias, daxsa o paniso, melones, calabazas, zebolas y quanto en ella se hallava de cosecha pendiente

86. AMC. Aguas, caja 15, s/n.

87. AMC. Aguas, caja 15, s/n. Sumaria información de testigos sobre un corte, efectuado por la villa de Almazora, en la venida de aguas de la acequia.

88. BALBÁS, 1892: 356.

89. Ibídem. 778 .

90. Ibídem. 872.

91. ROCAFORT, 1945: 87. 
y hasta en el cáñamo que avía estendido, ya en las viñas y algarrovos del secano $»^{92}$.

El segundo gran temporal de 1793 se materializó entre el 14 y el 15 de octubre, equiparable a la cantidad de agua caída en octubre de 1776 según Rocafort, «pues subió el agua del río Seco cinco palmos sobre el canal de la asequia de Coscollosa» e «inundó por una y otra parte, desde dicho canal hasta el mar, las partidas de las dos partes (...) haziéndolas todas una laguna», con lo que «derribó las baranas de piedra de la canal por donde passa la agua de la asequia Mayor ${ }^{93}$. Mientras esto sucedía en el campo, en la capital de la Plana se inundó nuevamente la Puerta del Olmo, así como diversas calles y casas, como la Casa de los Niños de San Vicente. En Vila-real, por su parte, se inundaron las calles y el convento del Carmen, así como el hospital, llegando el agua hasta los pies del Cristo que presidía su altar. Finalmente, en Nules el agua entró en la iglesia de los carmelitas descalzos «y llegó hasta el altar mayor», de «cinco gradas» de altura ${ }^{94}$.

Durante la segunda mitad de la década de los noventa, la nieve tuvo un gran protagonismo, puesto que nevó dos veces en el litoral castellonense. Primero, en febrero de 1796 y después en diciembre de 1799, cubriéndose todas las calles, aunque parece ser que no hubo grandes daños para la producción agrícola. Un suceso extraño a ojos de Rocafort, puesto que hay que recordar que Castelló solo está a 30 metros sobre el nivel del mar5.

\section{Las epidemias y las plagas}

Hasta ahora hemos comentado las principales adversidades meteorológicas del siglo XVIII. No obstante, hay que decir que, junto a éstas se produjeron otras de tipo biológico y sanitario igualmente importantes para la comprensión de la economía y la sociedad castellonense del Setecientos. Nos estamos refiriendo a las plagas y a las epidemias.

92. Ibídem. 88.

93. Ibídem. 88-89.

94. Ibídem.

95. ROCAFORT, 1945: 132. 
Por lo que respecta a las plagas ${ }^{96}$, aunque es cierto que algunas comarcas castellonenses, como el Alt Palància, fueron especialmente damnificadas por la langosta en los años cincuenta ${ }^{97}$, podría decirse que los cultivos de la Plana corrieron mejor suerte. Así pues, hasta la fecha, no existen testimonios documentales que avalen la existencia de ninguna gran catástrofe producida por estos $u$ otros insectos en los pueblos de la desembocadura del Millars. Más bien, lo que se custodia en los archivos del lugar son, precisamente, las medidas de prevención tomadas para evitar su llegada. En Castelló se llevaron a cabo rogativas en $1714^{98}$ y $1756^{99}$, además de llegar a esta ciudad la cabeza de san Gregorio Ostiense ${ }^{100}$ desde Navarra ${ }^{101}$. En Vila-real, por su parte, también se realizaron rogativas el 3 de agosto de $1756^{102}$.

Más complejo es el estudio de las epidemias del Setecientos. En el caso de la Plana se han documentado hasta nueve brotes infecciosos, especialmente a causa de los catarros y las calenturas. Estos dos síntomas, al contrario que el cólera y la peste, no eran brotes viajeros, sino que, en realidad, se encontraban bien asentados en las planicies mediterráneas ${ }^{103}$.

La década de los treinta fue, tal vez, la más prolífica para estos brotes, puesto que en ella se experimentaron tres. El primero fue en abril de 1730, cuando se tuvieron que celebrar rogativas en Castelló a causa de una «epidemia de catarros y mals de costats» ${ }^{104}$ que causó la muerte de muchas personas ${ }^{105}$. Ese año fueron enterradas en Castelló 498 personas, un 27,3\% más que la media de enterramientos del periodo $(1725-1729)^{106}$. El segundo fue en abril de 1739 , momento en que se celebraron nueve días de rogativas en Vila-real ${ }^{107}$

96. Véase: Alberola Romá, 21 (2003). Alberola Romá, 129, (2012).

97. BALBÁS, 1892: 462. «invadida toda la cuenca del Palancia por una plaga de lagosta» 98. AMC. Libre Verd, f. 171, V. ${ }^{\circ}$

99. AMC. Sesiones de Ayuntamiento, núm. 6, (24-7-1756).

100. AMC. Sesiones de Ayuntamiento, núm. 6, (03-10-1756).

101. Sobre esta práctica véase: BARRAGÁN, 29 (1978).

102. DOÑATE SEBASTIÀ, 1984: 89-90

103. Véase: Alberola Romá, 5 (1985).

104. AMC. Libre Verd, f. 177, V. ${ }^{\circ}$ BALBÁs, 1892: 77.

105. AMC. Sesiones de Ayuntamiento, núm. 2, (19-04-1730).

106. APSM, Libro de Bautizos, núm. 11.

107. CANDAU, 1907: 92 I 93. 
por «aver muchos enfermos con calenturas de mala especie» ${ }^{108}$. Tres años después, volvieron a aparecer «calenturas malignas» en Vila-real ${ }^{109}$, repitiéndose el mismo ceremonial religioso.

Hay que esperar hasta la década de los cincuenta para encontrar de nuevo adversidades de dicha índole. Así pues, en esta década hubo dos grandes epidemias. La primera tuvo lugar en Castelló durante los meses de marzo y abril de 1751, siendo necesaria la celebración de rogativas ${ }^{110}$ y la llegada de médicos forasteros ${ }^{111}$ «en vista de las enfermedades, que está padeciendo, con muchísimas muertes» ${ }^{112}$. La segunda gran epidemia se produjo entre los meses de mayo y junio de 1757, momento en que se manifestó en Vila-real «una enfermedad tan extraña, maligna y contagiosa, que en la casa que entraba solía postrar a toda la familia». Estas «fiebres malignas» afectaban sobre todo a «ancianos y alcoholizados por el abuso del aguardiente», tal y como describió posteriormente el cronista Candau, quien, desde un tono más literario que historiográfico, explicaba cómo afectaban estos brotes a la cotidianidad de una ciudad del Antiguo Régimen. Así pues, según él, los viajeros evitaron entrar en el municipio «por no contagiarse con el corrompido ambiente que en él se respiraba» y los propios vecinos de la localidad huían a los pueblos vecinos «abandonando sus casas e intereses», mientras que las mujeres y los ciegos, que permanecían allí, llevaban «varas del palio en los viáticos y las anillas de los féretros» ${ }^{113}$. Por otra parte, las fuentes primarias municipales apuntan que «las enfermedades (...) toman mucho cuerpo y son de malissima calidad y contagiosas», por lo que se hicieron rogativas sacando las imágenes de «la Virgen de Gracia, San Jaime, San Pascual Baylón, San Roque, San Alberto y otras» para «aplacar y dar consuleo» ${ }^{114}$.

Ante estas epidemias, era habitual que los médicos de la ciudad estuvieran saturados, motivo por el cual Candau narra que, en 1758, acudieron

108. AMVr. 86/1735, Libro de ayuntamientos y acuerdos celebrados por la justicia y regimiento de la presenta villa de Villarreal (24-4-1735).

109. AMVr. 88/1739, Judiciario del año 1739, (18-4-1739).

110. LORES, 1999: 187.

111. AMC. Sesiones de Ayuntamiento, núm. 5, (27-03-1751 y 23-04-1751).

112. AMC. Sesiones de Ayuntamiento, núm. 5, (24-03-1751).

113. CANDAU, 1907: 90-91.

114. DOÑATE SEBASTIÀ, 1984: 90. 
otros profesionales de Alcora, Borriana y Nules «para que juntamente con los tres que tenía la villa consultaran y deliberaran la especie de la dolencia y los medios para atacarla». Este procedimiento está igualmente documentado durante las fiebres de 1735, cuando el ayuntamiento de Vila-real pagó 400 libras a dos médicos de Borriana y Nules -Cristóbal Alonso y José Ramos- por haberse hecho cargo de los enfermos ${ }^{115}$, o en el Castelló de 1751, cuando se necesitó la ayuda extraordinaria de Ignacio Rocafort, «médico de su Magestad», así como de Cristóbal Alonso -que en aquel momento se encontraba trabajando en Alcora-, Humberto Campos de Hieles, Vicente Prats, Agustín Roca, José Castillo, Francisco Ximénez, Francisco Mollón y Pascual Silvestre. Todos ellos, junto a los médicos habituales de Castelló visitaron a todos los enfermos con el objetivo de diagnosticar un «concepto» conjunto ${ }^{116}$.

No obstante, la llegada de personal médico no era la única forma de cooperación entre las ciudades de la Plana en situaciones de extrema necesidad sanitaria. En 1770, Castelló ayudó económicamente a Orpesa «para socorrer las necesidades de las enfermedades» de aquella ciudad ${ }^{117}$. Parece ser que, estas ayudas económicas, fueron efectivas, puesto que en aquel año solo se enterraron 17 personas en Orpesa, una cifra más bien baja si tenemos en cuenta que en esta localidad se sepultó a una media de 38 individuos anuales entre 1763 y $1800^{118}$.

Ahora bien, no debemos pensar que las fiebres y los catarros eran las únicas enfermedades destacables del siglo. Es especialmente significativo, la ingesta de carne de «mala calidad»o «nociva para el público», que vendieron las carnicerías públicas de Castelló durante 1782. Una venta desafortunada que acabó con muchísimos enfermos y con los presuntos culpables -José Bungara y Pascual Nogués- declarando ante el ayuntamiento ${ }^{119}$.

Otra enfermedad que amenazó a las poblaciones del litoral castellonense fue la peste, aunque ésta afortunadamente no llegó a afectarles directamente en el siglo XVIII gracias al efectivo cordón sanitario existente. Para que esto

115. AMVr. 86/1735, Libro de ayuntamientos y acuerdos celebrados por la justicia y regimiento de la presenta villa de Villarreal (20-10-1735).

116. AMC. Sesiones de Ayuntamiento, núm. 5, (27-03-1751).

117. AMC. Sesiones de Ayuntamiento, núm. 9, (17-8-1770).

118. LÓPEZ Olivares, 59 (1983).

119. AMC. Sesiones de Ayuntamiento, núm. 10, (22-10-1782). 
fuese así, cabe destacar dos factores: por un lado, la prevención municipal y estatal, y por otro, la información recibida desde los sitios afectados. Los ejemplos de estas prácticas son muy comunes a lo largo del Setecientos. La primera de estas actuaciones se efectuó en 1720, en el contexto de la peste de Marsella, cuando el ayuntamiento de Vila-real, siguiendo la pragmática de 5 de octubre, cerró la mayoría de las puertas de las murallas para hacer una «averiguación de los que entren en la villa, porque el mal contagio de peste no se introduzca en ella», además de colocar un centinela en determinados puentes y cruces de caminos ${ }^{120}$. Otros avisos de peste fueron los llegados a Castelló en 1737 a causa de la «peste de los archipiélagos» ${ }^{121}$, en 1740 como consecuencia de los brotes surgidos en Argel y Tarifa ${ }^{122}$, en 1743 por la peste de Mesina ${ }^{123}$ o, finalmente, en agosto de 1786, cuando el II conde de Gausa, Félix de Muzquiz y Clemente, escribió una carta a este ayuntamiento para avisar del brote de peste supuestamente registrado en Venecia ${ }^{124}$.

\section{El ser humano frente a la catástrofe natural}

El Siglo de las Luces presenta una novedad en cuanto a la relación entre adversidad meteorológica y el ser humano. Ahora, en plena Ilustración, se vive una nueva valoración del papel del hombre frente a la naturaleza. Se experimenta un impulso en el conocimiento de las leyes que provocan los desastres naturales, de tal modo que se intenta argumentar de forma teórica la capacidad del hombre para actuar sobre el medio y controlarlo, tanto desde el punto de vista científico como técnico ${ }^{125}$.

En este contexto, desde las altas instancias de poder, la organización necesaria para reducir los efectos devastadores de la climatología adversa fue mucho más compleja que en centurias anteriores. Esta voluntad gubernamental puede verse con claridad en el programa político del reformismo borbónico $^{126}$, especialmente bajo los reinados de Carlos III y Carlos IV. Estas

\footnotetext{
120. AMVr. 78/1720, Judiciario del año 1720, (14-9-1720).

121. AMC. Sesiones de Ayuntamiento, núm. 2, (01-06-1737).

122. AMC. Sesiones de Ayuntamiento, núm. 3, (09-07-1740, 17-10-1740 y 04-11-1740)

123. AMC. Sesiones de Ayuntamiento, núm. 3, (26-07-1743)

124. AMC. Sesiones de Ayuntamiento, núm. 11.

125. Alberola RomÁ, 2010: 73.
}

126. Ibídem. 
medidas han dejado vestigios documentales en los archivos de la Plana, especialmente en el fondo Reales Cédulas y Decretos de Castelló, donde pueden encontrarse diversas órdenes preventivas contra plagas y epidemias redactadas por las altas instituciones de poder. Por poner un ejemplo, podemos citar las Instrucciones contra la plaga de langosta de $1756^{127}$.

Junto a estas medidas se encontraban las mejoras técnicas que podían llevarse a cabo, tanto desde la iniciativa municipal como desde la voluntad de los propios vecinos. Estas medidas eran, según Alberola, la mejora de los sistemas de riego, el drenaje y bonificación de marjales, albuferas y lagunas interiores, la construcción de embalses y las obras de carácter preventivo en los cauces y rieras ${ }^{128}$. En la Plana, estas mejoras técnicas son más que visibles en sus archivos municipales. Recordemos que en 1747 el ayuntamiento de Castelló consiguió el privilegio real para el aprovechamiento de las aguas de la Rambla de la Vídua ${ }^{129}$, siendo programadas toda una serie de actuaciones para conducir y usar sus aguas ${ }^{130}$. También cabe destacar la construcción de la Sèquia Nova de Castelló en 1789 ${ }^{131}$, la cual acabó con los continuos conflictos de esta villa con Almassora, con quien había compartido el azud y los primeros kilómetros de la acequia madre desde el siglo XIII. Así pues, experiencias de este tipo no tienen que ser interpretadas únicamente como un mecanismo para la ampliación de la superficie irrigada, sino que también pueden estudiarse como una manera de disminuir el daño ocasionado por las adversidades meteorológicas.

Estos dos proyectos eran de tal envergadura que necesitaron del beneplácito regio para ser iniciados. Además, sus elevados costes no estuvieron ajenos al conflicto, puesto que la financiación de ambas iniciativas tenía que correr a costa de unos vecinos que no siempre estaban a favor de ello. En el caso de la Rambla de la Vídua, este problema fue tan grave que el proyecto municipal

127. AMC. Reales Cédulas y Decretos, caja núm. 1, s/n. El alcance y contenido de estas instrucciones ya ha sido comentado por otros autores: PIQUERAS GARCÍA, 23 (1988). Alberola Romá, 21, (2003).

128. Alberola Romá, 2010: 71.

129. AMC. Aguas, caixa 14, núm. 88. Privilegio Real por el que se concede a la villa de Castellón el derecho a las aguas de la Rambla de la Viuda.

130. Véase: Gimeno MichaViLA, 1935.

131. Archivo Histórico Nacional (en adelante AHN). Consejos Suprimidos, legajo 8.271. 
Los efectos de la adversidad climática y sanitaria sobre la agricultura y la sociedad castellonense del siglo XVIII

no pudo llegar a materializarse con éxito. Hubo que esperar, al menos, hasta la década de 1770 para que se recuperara el interés por aquellas aguas, en aquel caso, mediante la iniciativa privada del fisiócrata Manuel Sisternes y del mercader Salvador Catalá. Este último fundaría, hacia 1790, el poblado de Benadressa, a orillas de dicha Rambla, mediante el fuero alfonsino ${ }^{132}$, aunque el proceso no culminaría completamente hasta el siglo XIX.

Junto a estas experiencias, existieron otras de menor magnitud, igualmente transcendentales, pero completamente desconocidas, puesto que tan solo son visibles tras el vaciado exhaustivo de los libros de actas y de los fondos ya citados anteriormente. Nos estamos refiriendo a pequeños trabajos diarios materializados por los propios campesinos para mejorar las infraestructuras de riego ya existentes. Por poner un ejemplo, en 1785, el labrador Baltasar Mas elevó un memorial al ayuntamiento de Castelló solicitando que se mejorara el sistema de acequias en las partidas Molinera y Semillar ${ }^{133}$, petición que, de alguna manera, debió de influir para que dos meses y medio después se llevara a cabo un nivelado de las acequias ${ }^{134}$. Y es que, durante toda la Edad Moderna, y en especial en el siglo XVIII, se mejoraron no solo las acequias madre sino también las menores, afianzándolas con piedra. Este proceso puede verse, por ejemplo, en 1752, momento en que el cantero Miguel Bueso construyó un hilo de piedra para un portillo de la acequia Costollosa de Castelló ${ }^{135}$.

Ahora bien, a pesar de la existencia de estas actuaciones técnicas, no es de extrañar que, en un escenario rural, con una coyuntura meteorológica tan inesperada e irregular, los labradores -siguiendo la mentalidad de la épocatrataran de acercarse a la religión para hacer frente a los duros golpes propinados por la naturaleza. En este contexto, es importante destacar el recurso a la rogativa, puesto que representa una valiosa referencia documental para conocer tanto las diferentes crisis agrícolas, como también la cultura, la mentalidad y la religiosidad de los castellonenses del Antiguo Régimen.

La rogativa es, según Alberola, «el recurs per excel.lència per a afrontar-se a catàstrofes singulars com ara llargs períodes de sequera, riuades, inundacions,

132. Sobre Benadressa véase: GIMÉNEZ FONT, 28 (2008).

133. AMC. Sesiones de Ayuntamiento, núm 11, (13/08/1785).

134. AMC. Sesiones de Ayuntamiento, núm 11, (26/10/1785).

135. AMC. Sesiones de Ayuntamiento, núm 5, (02/03/1752).

Revista de Historia Moderna, n. 35 (2017) (pp. 410-438) | ISSN-e: 1989-9823 | ISSN: 0212-5862 
terratrèmols, glaçades, pedregades o plagues agrícoles» ${ }^{136}$. Este recurso, estaba muy vinculado al miedo que sentía el campesino preindustrial hacia el desastre agrícola. Un miedo, que era alimentado, a su vez, por el clero local al relacionar estas situaciones con el lenguaje apocalíptico. Existía pues, un miedo primitivo a la ira de Dios, quien castigaba a sus fieles pecadores mediante adversidades. Una asimilación lógica -para ellos- si tenemos en cuenta que estos fenómenos naturales estaban, por lo general, relacionados con la pérdida de cosechas y, por tanto, con la pobreza y la penuria. No nos puede extrañar, pues, que el labrador de a pie se sintiera impotente para hacer frente con sus propias fuerzas a cualquier catástrofe natural, teniendo que levantar sus ojos al cielo para implorar ayuda divina mediante un conjunto de ritos y ceremonias de carácter religioso.

La convocatoria de rogativas era pedida por los ayuntamientos -tal y como se puede ver en los diferentes libros de actas municipales- pero, evidentemente, era la Iglesia quien daba el visto bueno y quien las materializaba. En Castelló las rogativas iban dirigidas unas veces a la Virgen del Lledó y otras al Santo Sepulcro, mientras que en Vila-real se hacían en honor a la Virgen de Gracia. En este último municipio, las rogativas se celebraban durante nueve días, tres las celebraba el clero de la Iglesia Mayor, otras tres los religiosos del convento de San Pascual, y, finalmente, las tres últimas los del convento del Carmen.

\section{Conclusiones}

En el presente artículo se ha realizado un exhaustivo vaciado de datos locales, que nos ha permitido ampliar los conocimientos sobre las adversidades climáticas, biológicas y sanitarias del Setecientos en la fachada mediterránea de la Península Ibérica, mediante un estudio de caso. A partir de ellos, trascendiendo la mera exposición anecdótica de episodios catastróficos, su interpretación nos ha permitido apreciar la pugna milenaria entre el medio físico -a lo largo de sus oscilaciones climáticas- y los actores de las sociedades preindustriales. Es evidente que el labrador castellonense del siglo XVIII estuvo continuamente amenazado por las sequías y los destrozos ocasionados por las

136. AlBerola Romá, 2010: 77-78.

Revista de Historia Moderna, n. 35 (2017) (pp. 410-438) | ISSN-e: 1989-9823 | ISSN: 0212-5862 
lluvias torrenciales, junto con determinados brotes de enfermedades infecciosas. No obstante, no faltaban mecanismos con los que prevenir y mitigar sus efectos. Como se ha podido ver, la existencia de eficientes instituciones de riego era imprescindible para distribuir el agua de forma adecuada cuando menos había, y, por tanto, más podían acentuarse las disputas entre sus usuarios. Éstas no solo se encargaban de distribuir este preciado recurso de uso común y vigilar las posibles infracciones, sino que, junto a los ayuntamientos, conseguían coordinar rápidamente la reparación de cualquier destrozo que las lluvias torrenciales pudieran causar en las acequias, sin olvidarnos de las continuas mejoras de las infraestructuras hídricas castellonenses acometidas durante el siglo. Junto a estas actuaciones en materia de riego, hemos podido observar cómo las carestías de cereales ocasionadas por las sequías, eran mitigadas eficientemente gracias a la actuación de los consistorios y las complejas redes de abastecimiento de trigo, evitando así elevadas subidas en los precios. Por último, también hemos advertido la eficacia de los cordones sanitarios a la hora de evitar la difusión de epidemias tan graves como la peste y la solidaridad entre municipios para erradicar otros contagios.

\section{Agradecimientos}

Quisiera agradecer la ayuda prestada por Amparo Felipo Orts y Carmen Pérez Aparicio durante la redacción de este artículo, así como los consejos de Armando Alberola Romá y de los evaluadores anónimos.

\section{Bibliografía}

Alberola Romá, Armando, «Una enfermedad de carácter endémico en el Alicante del XVIII: las fiebres tercianas», Revista de Historia Moderna, Anales de la Universidad de Alicante, 5 (1985): 127-140. http://dx.doi.org/10.14198/ RHM1985.5.03

Alberola RomÁ, Armando, «Procesiones, rogativas, consejos y exorcismos: el campo valenciano ante la plaga de langosta de 1756», Revista de historia moderna, Anales de la Universidad de Alicante, 21 (2003): 383-410. http:// dx.doi.org/10.14198/RHM2003.21.17

Alberola RomÁ, Armando, «Sequía, lluvias torrenciales y transporte fluvial de madera: las avenidas del río Turia del otoño de 1776», Revista de Historia 
Los efectos de la adversidad climática y sanitaria sobre la agricultura y la sociedad castellonense del siglo XVIII

Moderna: Anales de la Universidad de Alicante, 23 (2005): 49-74. http://dx.doi. org/10.14198/RHM2005.23.03

AlBerola RomÁ, Armando, Quan la pluja no sap ploure: sequeres i riuades al País Valencià en l'edat moderna, València, Publicacions Universitat de València, 2010.

Alberola RomÁ, Armando, «Plagas de langosta y clima en la España del siglo XVIII», Relaciones. Estudios de Historia y Sociedad, 129 (2012): 21-50. Disponible en: http://www.scielo.org.mx/scielo. php?script=sci_arttext\&pid=S0185-39292012000100002\&lng=es\&nrm=iso Alberola RomÁ, Armando, Los cambios climáticos: la pequeña Edad de Hielo en España, Madrid, Cátedra, 2014.

Balbás, Juan Antonio, La Virgen del Lidón, Castelló de la Plana, Armengot, 1890. BAlBÁs, Juan Antonio, El libro de la Provincia de Castellón, Castelló de la Plana, Caja de Ahorros y Monte de Piedad de Castellón, 1892.

BARRAGÁN LANDA, Juan José, «Las plagas del campo español y la devoción a San Gregorio Ostiense» Cuadernos de etnología y etnografía de Navarra, 29 (1978): 273-298. Disponible en: http://www.vianayborgia.es/CUET-00290000-0273-02981.html

Barriendos Vallvé, Mariano y Llasat Botija, María del Carmen, «El caso de la anomalía «Maldá» en la cuenca mediterránea occidental (1760-1800). Un ejemplo de fuerte variabilidad climática», en Armando Alberola Romá y Jorge Olcina Cantos (Coords.), Desastre natural, vida cotidiana y religiosidad popular en la España moderna y contemporánea, Alicante, Universidad de Alicante, 2009.

Bellver Sanz, Luís, Historia de Castellón de la Plana. Castelló de la Plana, El clamor de Castellón, 1888.

Bernat MARTí, Joan Serafí (coord.), Les sèries vitals valencianes, Volum I. Les comarques septentrionals. València, Seminari d'Estudis sobre la población del País Valencià, 1996.

CANDAU, Juan Bautista, La gracia en Villarreal: memoria histórico-descriptiva de la Imagen y Culto de Nuestra Señora de Gracia venerada en la ciudad de Villarreal. Tortosa, Imprenta de José L. Foguet, 1907.

CAVANILLES. JOSEPH, Observaciones sobre la Historia natural, geográfica, agricultura, población y frutos del Reyno de Valencia, Madrid, Imprenta Real, 1795, 2 vols. DoÑate SEBASTiÀ, José María, Datos para la historia de Villarreal, vol. 6, Vila-real, Edicions Anubar, 1986. 
Los efectos de la adversidad climática y sanitaria sobre la agricultura y la sociedad castellonense del siglo XVIII

FAUS PRIETO, Alfredo, «La ciudad de Valencia ante las riadas del Túria de 1776», Cuadernos de geografía, 65-66 (1999): 123-142. Disponible en: http://roderic. uv.es/handle/10550/31039

GARRABOU SEgURA, Ramon, Un fals dilema: modernitat o endarreriment de l'agricultura valenciana (1850-1900), València, Institut Alfons el Magnànim, 1985.

GARrido Herrero, Samuel, Cànem Gentil: l'evolució de les estructures agràries de la Plana de Castelló (1750-1930), Castelló de la Plana, Ajuntament de Castelló de la Plana, 2004.

GIMÉNEZ FONT, Pablo, «Colonización territorial, razón ilustrada y particularidades valencianas en la nueva población de Benadressa (Castellón de la Plana)» Cuadernos de Geografía, 28 (2008): 61-80. Disponible en: http://hdl.handle. net/10045/33101

Gimeno MichaVila, Vicente, La Rambla de la Viuda: antecedentes históricos y estudio de las concesiones de aprovechamiento de sus aguas, Castelló de la Plana, Societat Castellonenca de Cultura, 1935.

Le Roy LadURIE, Enmanuel, Historia del clima desde el año mil, México D.F., Fondo de Cultura Económica, 1991.

LÓPEZ OlivarES, Diego, «Estudio sobre la demografía histórica de Orpesa» Boletín de la Sociedad Castellonense de Cultura. 59 (1983): 359-367.

LORES MESTRE, Beatriz, Fiestas y arte efímero en el Castellón del setecientos, Castelló de la Plana, Universitat Jaume I, 1999.

Membrado Tena, Joan Carles, Vila-Real, ciutat industrial: el taulell i altres indústries en la història, el present i el futur de la ciutat, Vila-Real, Ajuntament de Vila-Real, 1995.

PiQUeras GARCíA, María Belén, «Una amenaza para la agricultura de Almansa: las plagas de langosta (1756-1759)», Al-Basit: Revista de estudios albacetenses, 23 (1988): 189-201. Disponible en: http://www.iealbacetenses.com/index. php? menu=6\&ruta $=2 \&$ id $=50$ \&opcion $=2 \&$ pagina $=2$

Quereda SAla, José, «Clima e hidrología», en La provincia de Castellón de la Plana. Tierras y Gentes. Castelló de la Plana. Caja de Ahorros y Monte de Piedad de Castellón, 1985.

ROCAFORT, Josep, Libro de cosas notables de la villa de Castellón de la Plana, Castelló de la Plana, Sociedad Castellonense de Cultura, 1945.

Traver García, Benito, Historia de Villarreal, Vila-real, Botella, 1909.

TraVer García, Benito, Efemérides de Villarreal, Vila-real, Botella, 1935. 